\title{
Spatial Dimensions of the Unemployment Rate in Jordan 2008
}

\author{
Faisal G. Khamis \\ AL-Zaytoonah University of Jordan, Amman, Jordan
}

\begin{abstract}
Although many studies examined the existence of spatial pattern of unemployment in some developing and many developed countries in improving the prosperity or social status and reducing the inequalities in unemployment between areas of such country, there is still much work to be done. Some of these studies found spatial pattern for unemployment using different statistical techniques and geographical mapping. The question is raised whether such a spatial pattern exists in Jordan? The objective is to investigate the spatial structure of unemployment rate (UR) across different governorates to provide implications for policy makers, investigating the hot spots of UR and showing optical picture of UR. The study design is cross-sectional, where the data are collected for 12 governorates based on the census in 2008. A mapping using quartiles is used as a first step to conduct a visual inspection of UR. Two statistics of spatial autocorrelation, based on sharing boundary neighbours, known as global and local Moran's I, were carried out for examining the global clustering and local clusters, respectively. Out of 12, three governorates (Balqa, Zarqa, and Tafiela) are found as local clusters in UR. In conclusion, the UR varies in the visual inspection based on choropleth mapping across different governorates with black spots in the northwestern, central and southeastern part of the country. Statistically, no significant global clustering can be found, but several significant local clusters are found in the central and western part of the country.
\end{abstract}

Zusammenfassung: Obwohl viele Studien die Existenz eines räumlichen Musters der Arbeitslosigkeit in einigen Entwicklungsländer und vielen entwickelten Ländern untersuchten, wobei die Verbesserung des Wohlstands oder des sozialen Statuses und die Reduzierung der Ungleichheit in der Arbeitslosigkeit zwischen Gebieten solcher Länder betrachtet wurden, gibt es noch viel Arbeit zu tun. In einigen dieser Studien fand man räumliche Muster für die Arbeitslosigkeit, wobei verschiedene statistische Techniken und geografische Abbildungen verwendet wurden. Es stellt sich die Frage, ob eine räumliche Struktur auch in Jordanien existiert. Das Ziel ist, die räumliche Struktur der Arbeitslosigkeitsrate (UR) über diverse Gouvernemente zu untersuchen, um Implikationen für Parteiideologen zur Verfügung zu stellen, indem man die Krisenherde von UR erkundet und ein optisches Bild der UR zeigt. Das Studiendesign war eine Querschnittsstudie, in der die Daten für 12 Governemente basierend auf die Volkszählung 2008 gesammelt wurden. Eine kartografische Abbildung beruhend auf Quartile wird als ein erster Schritt verwendet um eine visuelle Prüfung der UR durchzuführen. Zwei Statistiken der räumlichen Autokorrelation wurden betrachtet, welche auf die gemeinsame Nutzung von Grenznachbarn beruhen, bekannt als globales und lokales 
Moran's $I$, um das globale Clustering und lokale Cluster zu untersuchen. Von den 12 finden sich drei Governemente (Balqa, Zarqa und Tafiela) als lokale Cluster in UR. Schließlich variiert die UR in den visuellen Betrachtungen beruhend auf Choroplethenkarten über die verschiedenen Gouvernemente mit Gefahrenstellen im nordwestlichen, zentralen und südöstlichen Teil des Landes. Statistisch gesehen, kann kein signifikantes globales Clustering gefunden werden, aber mehrerer signifikante lokale Cluster werden im zentralen und westlichen Landesteil gefunden.

Keywords: Spatial Autocorrelation, Unemployment, Mapping, Global and Local Moran Statistics, Governorates of Jordan.

\section{Introduction}

Unemployment is one of the main socioeconomic issues, which negatively affects both economic activity and social life. In recent years, there has been a growing interest in examining the existence of spatial autocorrelation of the UR and its spatial relationship to many indicators such as poverty, education, ..., etc. Low wage flexibility and limited labour mobility involve persistent unemployment differentials across governorates in Jordan. In contrast, the present paper focuses on the spatial structure of unemployment disparities across governorates. Governorates are tightly linked by emigration, commuting, and governorate trade. These types of spatial interaction are exposed to the frictional effects of distance, possibly causing the spatial dependence of governorate labour market conditions. Governorates marked by high or low unemployment tend to cluster in space.

The UR was studied in many countries using different statistical measures. Evidence provided by Eichengreen (1993) and indicated that the responsiveness of unemployment differentials is much greater in the US than in Europe. Bertola (1999) as well as Blau and Kahn (1999) analyzed the impact of different institutions and regulations on labour market outcomes. According to their results, wage adjustment and labour mobility are effected by minimum-wage provisions unemployment benefits and welfare payments. However, the results of Layard (1997) implied that strict labour market regulations, employment protection and minimum wages not be the main target areas of policies aiming at a significant decline of unemployment. Instead they advice reform of social security systems combined with active labour market policies.

A common feature of most of the above mentioned studies is that they investigated the functioning of labour market adjustments and the effects of labour market regulations without considering the spatial dimension of area labour market disparities. Some studies investigated the wage curve taking spatial effects into account. Manning (1994) and Buettner (1999) analyzed the relationship between earnings and unemployment for British countries and German regions respectively. An analysis by Molho (1995) confirmed that there is significant spatial interaction among regional labour markets in the UK. Overman and Puga (2002) analyzed unemployment clusters across European regions. The results of their nonparametric approach indicted that unemployment rates are much more homogeneous across neighbouring areas than across regions in the same EU country. The results found by Filiztekin (2007) indicated that the provincial unemployment 
rates were quite persistent and the gap across different regions widens further with spatial clusters emerging across Turkey. Lopez-Bazo, Barrio, and Artis (2000) discussed the role of neighbouring effects in explaining the spatial distribution of unemployment, where their results pointed to the emergence of at least two clusters in the regional distribution of unemployment rates in Spain.

To understand the linkages between socioeconomic variables, investigations should focus on features of the areas rather than on the compositional characteristics of residents of the area, which can not fully describe the social environment in which people live (Macintyre, Maciver, and Sooman, 1993). So, spatial autocorrelation and geographical pattern of UR were studied by the author. Spatial autocorrelation is the term used for the interdependence of the values of a variable over space. However, it was argued that lattice data are spatially correlated, where exploratory spatial data analysis (ESDA) was used using lattice data. The ESDA quantifies the spatial pattern in order to increase the analyst's knowledge of the spatial system. As well as mapping plays an important role in the monitoring of unemployed people. Maps can reveal spatial patterns not previously recognized or suspected from the examination of a table of statistics and reveal high risk communities or problem areas (Lawson and Williams, 2001). The purpose of spatial analysis is to identify pattern in geographic data and attempt to explain this pattern. Findings are expected to enhance unemployment monitoring and policing interventions across governorates in Jordan.

Reducing unemployment inequalities was not primary objective but emergent prosperity. The importance of my goal or purpose was followed from such argument stated that unemployment is a standard indicator for poverty status of the population. Cattaneo (2006) stated that a strong link existed between poverty and unemployment, being the lack of employment one of the main determinants of poverty. According to the study in Jordan by Amerah (1993), health was affected negatively by unemployment, where Amerah stated that since the mid-1980s unemployment had become a serious problem in Jordan, manifesting a widening gap between the demand for and supply of labour. Elhorst (2003) proposed several reasons that make studying the spatially uneven distribution of unemployment worthwhile. One of these reasons is the wide unemployment differentials imply inefficiency in the economy as a whole and reduces growth. Also, to author's knowledge there was no studies used the spatial analysis techniques and geographical mapping in studying the inequalities in unemployment gradient in Jordan. As well as the studies which used other advanced statistical techniques, such as structural equations modeling, in examining the inequalities of unemployment were very limited in Jordan. Furthermore, the importance of mapping is followed from what Koch (2005) stated: why make the map if detailed statistical tables carry the same results? Perhaps the most important reason for studying spatial statistics is not only interested in answering the "how much" question, but the "how much is where" question (Schabenberger and Gotway, 2005). In light of these: (1) the existence of spatial global clustering and (2) spatial local clusters of governorates with respect to UR were investigated. This study contributes to the literature by examining the geographical distribution of UR, spatial global clustering and local clusters of unemployment. The study design was a cross-section analysis in a census survey conducted in Jordan in 2008.

The data analysis followed five steps. In step 1, the levels of UR were visually in- 
spected using the quartiles based on choropleth mapping. Step 2 included the calculation of global Moran's $I$ for UR to detect the global clustering and also the significance of $I$ statistic was examined using permutation test. Step 3 involved the calculation of local Moran's $I_{i}$ for each $i$ th governorate to detect the local clusters of UR and also the $p$-values of local Moran's $I_{i}$ values are calculated using Monte Carlo simulation. In step 4 the gradients of quartiles of local Moran values and their $p$-values are visually inspected. In conclusion, no spatial global clustering was found, but local clusters in UR were found. The major contribution was the demonstration that spatial locations had statistically significant effects on the likelihood and disparity of UR.

\section{Materials and Methods}

Data: The data were collected from the department of statistics, statistical yearbook, based on census conducted in Jordan in 2008. For each of $N=12$ governorate, UR was used. The UR is defined as the percentage of unemployed persons in the total economically active population (the total of unemployed and employed persons). Unemployed person is a person aged (15) years and more, who is without work, able to work, available for work and is looking for work.

Analysis: Data analysis involved five steps. In step 1, the UR was tested for normal distribution, where it was found to follow approximately normal distribution. In step 2, visual inspection based on the quantified gradients for UR using quartiles was conducted. Step 3 included the calculation of global Moran's $I$ for UR to detect the global clustering and also the significance of $I$-statistic using permutation test was examined. Step 4 involved the calculation of local Moran's $I_{i}$ for the $i$ th governorate and it's $p$-value using Monte Carlo simulation to detect the local clusters of UR. In step 5, using quartiles, visual inspection for the gradients of local Moran values and their $p$-values were inspected based on choropleth mapping.

Based on global Moran's I, the geographical distribution of UR can be tested for whether it was random or not. Also, the author was interested in detecting and evaluating local clusters using local Moran's $I_{i}$ statistic. In regional data analysis, governorates in close proximity to one another with similar values produce a spatial pattern indicative of positive spatial autocorrelation. Identifying groups of governorates in close proximity to one another with high values was often of particular interest suggesting a "cluster" of elevated risk.

The UR values were categorized into four intervals. These intervals were used for all maps using darker shades of gray to indicate increasing values of UR. Such approach enables qualitative evaluation of spatial pattern. In the neighbourhood researches, neighbours may be defined as governorates which border each other or within a certain distance of each other. In this research neighbouring structure was defined as governorates which share a boundary. The second order method (queen pattern) which included both the first-order neighbours (rook pattern) and those diagonally linked (bishop pattern) was used, i.e., queen method makes links in all eight directions. A neighbourhood system for Jordan's governorates was given in Table 1 in the last column, where the ID neighbours for each governorate were shown. 
A choropleth map was used commonly to portray data collected for units, such as counties, districts, states or governorates. To construct a choropleth map, data for enumeration governorates were typically grouped into classes and a gray tone was assigned to each class. Although maps allow us to visually assess spatial pattern, they have two important limitations: their interpretation varies from person to person, and there is the possibility that a perceived pattern is actually the result of chance factors, and thus not meaningful. For these reasons, it makes sense to compute a numerical measure of spatial pattern, which can be accomplished using spatial autocorrelation. Global spatial clustering and local spatial clusters were identified.

Identification of global spatial clustering: The goal of a global index of spatial autocorrelation is to summarize the degree to which similar observations tend to occur near to each other in geographic space. In this exploratory spatial analysis, the spatial autocorrelation using standard normal deviate ( $z$-value) of Moran's $I$ under normal assumption was tested. Moran's $I$ is a coefficient used to measure the strength of spatial autocorrelation in regional data and provides also a test for unemployment clustering. The interpretation of the Moran statistic is as follows: If $I>\mathrm{E}(I)$, then a governorate tends to be connected to the governorates that have similar attribute values and vice versa. Global clustering test was used to determine whether clustering was existed throughout the study area, without determining statistical significance of local clusters. The autocorrelation coefficient can be used to test the null hypothesis of no spatial autocorrelation or spatially independent versus the alternative of positive spatial autocorrelation:

$$
\begin{aligned}
& H_{0} \text { : No clustering exists (no spatial autocorrelation) } \\
& H_{1} \text { : Clustering exists (positive spatial autocorrelation) }
\end{aligned}
$$

Moran's $I$ is a weighted correlation coefficient used to detect departures from spatial randomness. It was used to determine whether neighbouring areas were more similar than would be expected under the null hypothesis. It was calculated as follows (Cliff and Ord, 1981):

$$
I=\frac{N \sum_{i=1}^{N} \sum_{j=1}^{N} w_{i j}\left(x_{i}-\bar{x}\right)\left(x_{j}-\bar{x}\right)}{S_{0} \sum_{i=1}^{N}\left(x_{i}-\bar{x}\right)^{2}}, \quad \text { with } \quad S_{0}=\sum_{i=1}^{N} \sum_{j=1}^{N} w_{i j}, \quad i \neq j,
$$

where $N=12$ was the number of governorates, the $w_{i j}=1$ was a weight denoting the strength of the connection between two governorates $i$ and $j$ that shared a boundary, otherwise, $w_{i j}=0, x_{i}$ and $x_{j}$ represents the UR in $i$ th and $j$ th governorate, respectively.

A significant positive value of Moran's $I$ indicates positive spatial autocorrelation, showing the overall pattern for the governorates having a high/low level of unemployment similar to their neighbouring governorates. A significant negative value for Moran's $I$ indicates negative spatial autocorrelation, showing the governorates having a high/low level of unemployment unlike neighbouring governorates. To test the significance of global Moran's $I, z$-statistic which follows a standard normal distribution was applied. It was calculated as follows (Weeks, 1992):

$$
z=\frac{I-\mathrm{E}(I)}{\sqrt{\operatorname{var}(I)}} .
$$


A permutation test was used. What a permutation test tells us is that a certain pattern in data was or was not likely to have arisen by chance. The observations of UR were randomly reallocated 1000 times with 1000 of spatial autocorrelations were calculated in each time to test the null hypothesis of randomness. That is to say, the hypothesis under investigation suggests that there will be a tendency for a certain type of spatial pattern to appear in data, whereas the null hypothesis says that if this pattern was present then this was a purely chance effect of observations in a random order. The analysis suggested an evidence of clustering if the result of the global test was significant but it didn't identify the locations of any particular clusters. Beside, clustering which represent global characteristic of unemployment, the existence and location of localized spatial unemployment clusters in the study population are of interest in geographic sociology. Accordingly, local spatial statistic was advocated for identifying and assessing potential hot spots or clusters.

Identification of local spatial clusters: A global index can suggest clustering but cannot identify individual clusters (Waller and Gotway, 2004). Local Indicators of Spatial Associations (LISAs) measure the degree of spatial dependence to allow for the effects of neighbourhood based on each governorate associated value of UR. The main purpose of such index is to provide a local measure of similarity between each governorate's associated value and those of nearby or surrounded governorates. Anselin (1995) proposed the local Moran's $I_{i}$ statistic to test the local autocorrelation, where local spatial clusters, sometimes referred to as hot spots, may be identified as those locations or sets of contiguous locations for which the local Moran's $I_{i}$ was significant. Anselin stated that the indication of local patterns of spatial association may be in line with a global indication, although this is not necessarily be the case. It is quite possible that the local pattern is an aberration that the global indicator would not pick up, or it may be that a few local patterns run in the opposite direction, which was the case that was found in this study, of the global spatial trend. However, Moran's $I_{i}$ for $i$ th governorate may be defined as (Waller and Gotway, 2004):

$$
I_{i}=\frac{x_{i}-\bar{x}}{S} \sum_{j=1}^{N} \frac{w_{i j}}{\sum_{k=1}^{N_{i}} w_{i k}} \frac{x_{j}-\bar{x}}{S}, \quad i=1, \ldots, 12,
$$

where, analogous to the global Moran's $I$, the $x_{i}$ and $x_{j}$ represents the UR in the $i$ th and $j$ th governorate respectively, $N_{i}$ is the number of neighbours for the $i$ th governorate, and $S$ is the standard deviation of UR. It was noteworthy that the number of neighbours for the $i$ th governorate were taken into account in the $I_{i}$ statistic by the amount $w_{i j} / \sum_{k=1}^{N_{i}} w_{i k}$, where $w_{i k}$ was measured in the same manner as in Moran's $I$ statistic. Local Moran statistic was used to test the null hypothesis of no clusters. However, local Moran statistic is a decomposition of global Moran's $I$ into the contributions of small areas.

The typical output of a LISA analysis involves the values of the LISAs themselves, which were typically mapped to indicate areas with high values, suggesting stronger local autocorrelation than others. LISA values may be due to aggregations of high values, aggregations of low values, or aggregations of moderate values. Thereby, high values of $I_{i}$ suggested clusters of similar (but not necessarily large) values across several governorates, and low value of $I_{i}$ suggested an outlying cluster in a single governorate $i$ (being 
different from most or all of its neighbours). A positive local Moran value indicates local stability, such as governorate that has high/low UR surrounded by governorate that has high/low UR. A negative local Moran value indicates local instability, such as governorate has low unemployment surrounded by governorate has high unemployment or vice versa. However, each governorate's $I_{i}$ value can be mapped to provide insight into the location of governorates with comparatively high or low local association with their neighbouring values. In the statistical analysis, all programs are performed under the S-PLUS 8 software.

\section{Results}

Descriptive statistics were calculated for UR, where the mean and standard deviation were found to be 14.94 and 2.95, respectively; skewness and kurtosis were found to be 0.25 and 0.73 , respectively. The five-number summary of UR data set consists of the minimum, maximum and quartiles written in increasing order: $\min =9.70, Q_{1}=13.15$, $Q_{2}=14.95, Q_{3}=16.25$, and $\max =20.90$. From the five-number summary, the variations of the four quarters of the UR data are found 3.45, 1.80, 1.30, and 4.65, respectively, where the fourth quarter has the greatest variation of all. As shown in Table 1, Ma'an governorate accounted for the highest rate of unemployment $(20.90 \%)$. It was followed by the governorates of Karak and Tafiela, as accounted for $18.20 \%$ and $16.60 \%$, respectively. The lowest rate was in the governorate of Amman with $9.70 \%$, despite the fact that Amman had the largest population relative to other governorates. This can be explained by the persistent growth of economic activity in most fields, which provide more job opportunities, especially for those who have academic qualifications. However, the UR in Jordan decreased slightly from $19.7 \%$ in 1993 to $12.7 \%$ in 2008 .

Figure 1 shows the study area explaining all governorates with their identification numbers (ID) and visual insight for UR, respectively. An overall worsening pattern (higher scores) for UR was found in the mid and southern part of the country. The suggestion of spatial clustering of similar values that follows from a visual inspection of mapping for UR was not confirmed by a positive significant global Moran's $I$ of 0.10 with an associated standard normal $z$-value of 1.23 and $p$-value of 0.218 . In the investigation of global clustering, permutation test should be done, where the permutation $p$-value of 0.104 was found not significant. Thus, the null hypothesis of no spatial autocorrelation was not rejected. What a permutation test tells us is that a certain pattern in data is or is not likely to have arisen by chance. The observations were randomly reallocated 1000 times to test the null hypothesis of randomness. That is to say, the hypothesis under investigation suggests that there will be a tendency for a certain type of spatial pattern to appear in data, whereas the null hypothesis says that if this pattern is present then this is a purely chance effect of observations in a random order.

Since local Moran's $I_{i}$ varied by location, it was more easily interpreted visually by colour coding for each governorate. Therefore, the spatial pattern of local Moran values of UR was illustrated in Figure 2 (left part) with darkest shade corresponding to the highest quartile. The right part of Figure 2 showed the levels of $p$-values of local Moran values. These maps displayed geographical inequalities across governorates of Jordan. Three 

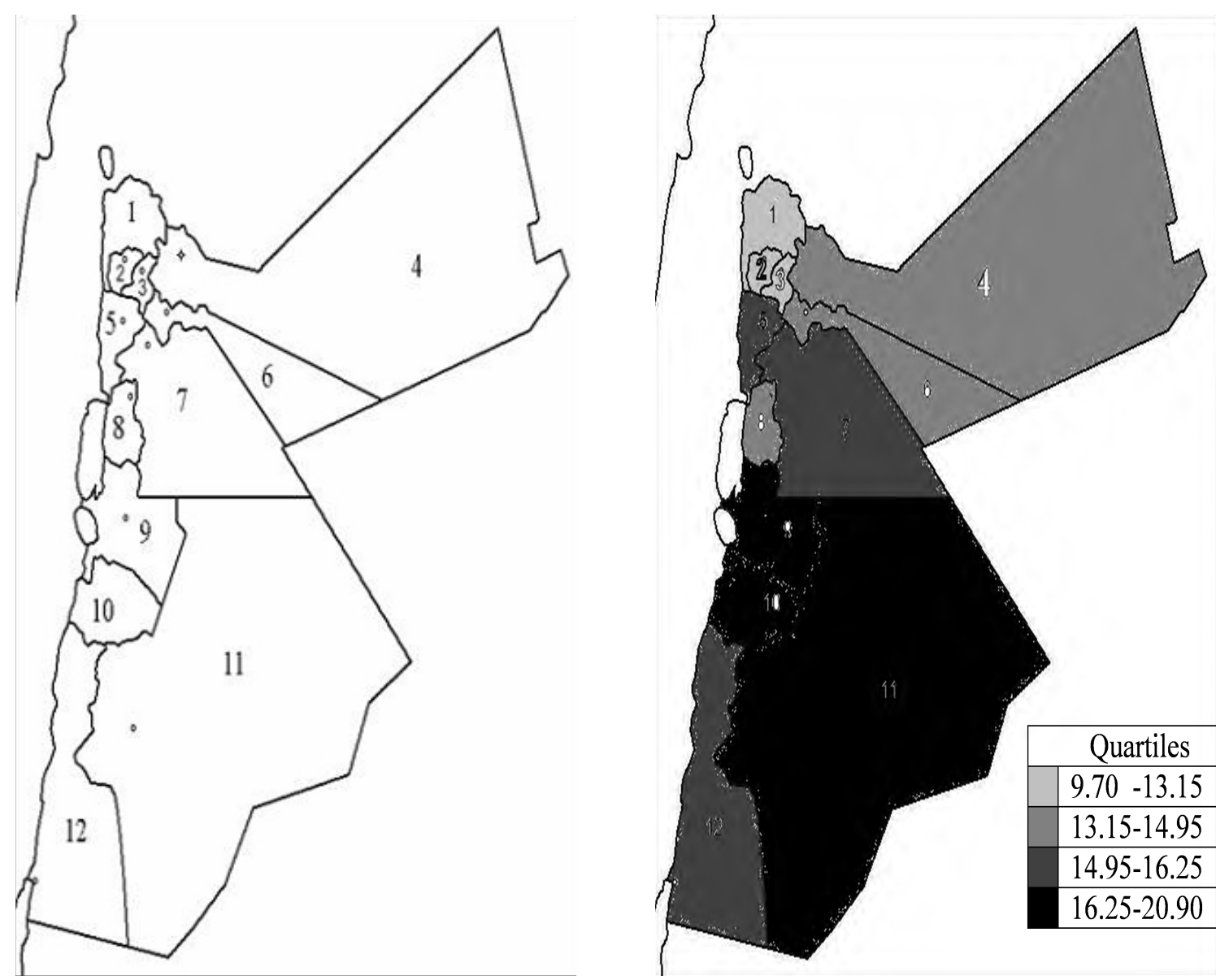

Figure 1: Left: study area with all Governorates and their identification numbers: Irbid (1), Ajlun (2), Jarash (3), Mafraq (4), Balqa (5), Zarqa (6), Amman (7), Madaba (8), Karak (9), Tafiela (10), Ma'an (11), Aqaba (12). Right: Choropleth map showing URs.

significant clusters were found, where their ID were: 5, 6, and 10 to have higher level in UR compared to other governorates as shown from their local Moran values and their $p$-values in Table 1, where the significance values are shown in boldface.

The autocorrelation coefficient was sensitive to the choice of spatial neighbours and spatial weights, so it was desirable to run the spatial autocorrelation under several different scenarios. Therefore, permutation distribution can be used to test the significance of the autocorrelation statistic of Moran's $I$. Thus, a 1000 random permutations were used, where the $p$-value of 0.104 was found. Simulated data are useful for validating the results of spatial analysis. However, using Monte Carlo simulation, 9999 random samples, 12 values for each sample, were simulated. The process of simulation was conducted under standard normal distribution with mean zero and standard deviation one to calculate the $p$-values for local Moran values of UR. When the word simulation is used, it is referred to an analytical method meant to imitate a real-life system, especially when other analyses are too mathematically complex or too difficult to reproduce. While results were specific to these data, the case study helps identify general concepts for future study. 
Table 1: Explains the UR, Local Moran's $I_{i}$ with its corresponding $p$-value and ID neighbours for each $i$ th governorate.

\begin{tabular}{l|rrrl}
\hline ID & UR (\%) & $I_{i}$ & $p$-value & ID neighbours \\
\hline 1 & 9.70 & -0.08 & 0.598 & $2,3,4,5$ \\
2 & 12.80 & 0.00 & 0.433 & $1,3,5$ \\
3 & 11.60 & -0.14 & 0.704 & $1,2,4,5,6,7$ \\
4 & 14.60 & 0.10 & 0.280 & $1,3,6$ \\
5 & 15.90 & 0.31 & $\mathbf{0 . 0 4 2}$ & $1,2,3,6,7,8$ \\
6 & 13.50 & 0.78 & $\mathbf{0 . 0 0 8}$ & $3,4,5,7$ \\
7 & 15.60 & -0.41 & 0.892 & $3,5,6,8,9,11$ \\
8 & 14.80 & 0.05 & 0.336 & $5,7,9$ \\
9 & 18.20 & 0.19 & 0.163 & $7,8,10,11$ \\
10 & 16.60 & 0.60 & $\mathbf{0 . 0 5 0}$ & $9,11,12$ \\
11 & 20.90 & -0.03 & 0.506 & $7,9,10,12$ \\
12 & 15.10 & 0.07 & 0.351 & 10,11 \\
\hline
\end{tabular}
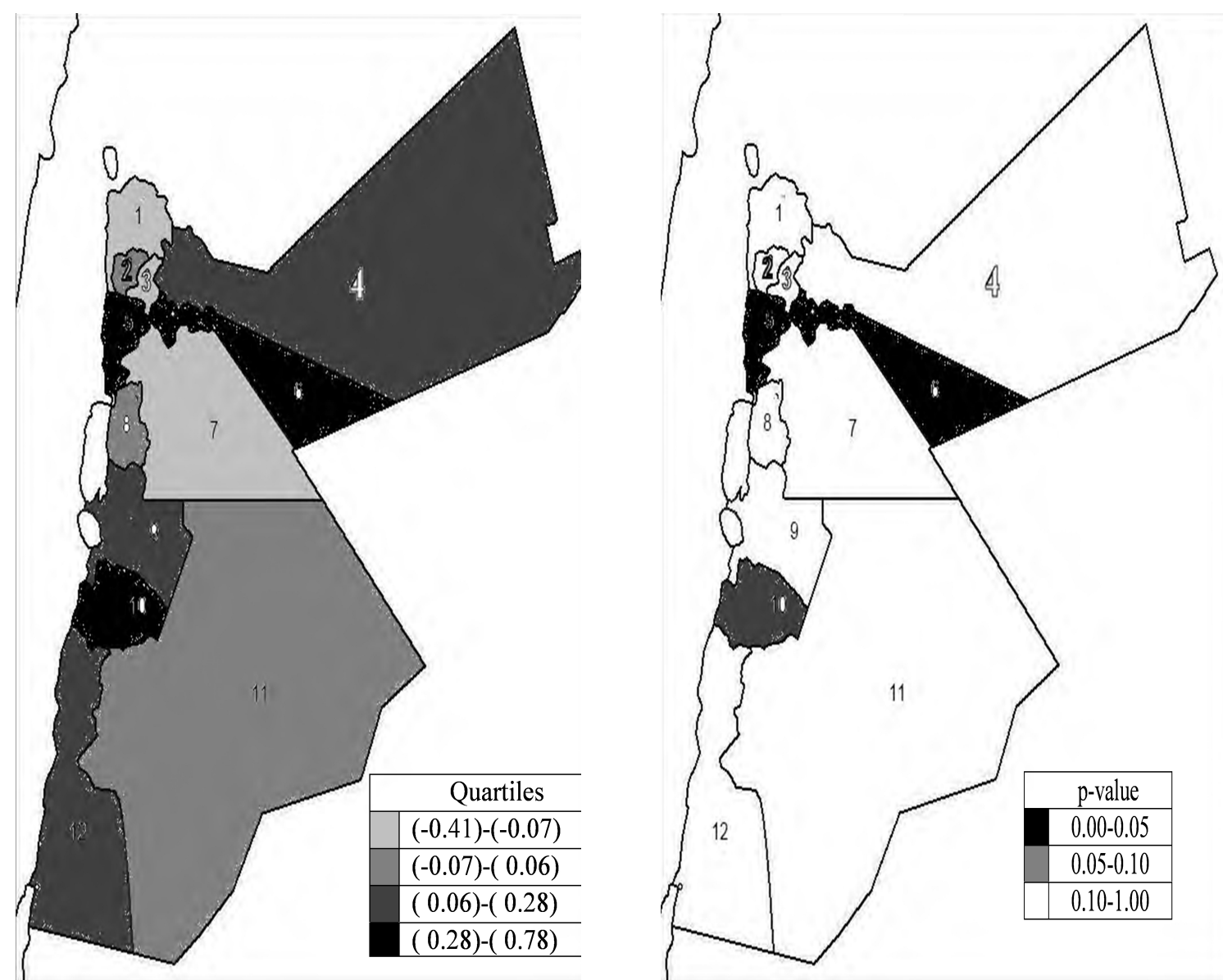

Figure 2: Left: Choropleth map showing local Moran values of UR. Right: Choropleth map showing $p$-values of local Moran values. 


\section{Discussion}

This study, undertaken in Jordan, quantified the spatial autocorrelation of UR. Spatial global clustering and local clusters for UR were examined based on global Moran's $I$ and local Moran's $I_{i}$ respectively. Such findings allow policy makers to better identify what types of resources are needed and precisely where they should be employed. The above framework proposed for analyzing the spatial pattern of UR revealed some noteworthy findings. After accepting the null hypothesis, concluding that there wasn't form of global clustering, it was of course of interest to know the exact nature of UR. Are there hot-spot clusters? If so, how many hot-spots are there and where are they located?

Exploratory tools were used such as descriptive table and somewhat small area choropleth maps. Maps provide a powerful means to communicate data to others. Unlike information displayed in graphs, tables and charts, maps also provide bookmarks for memories. In this way, maps were not passive mechanism for presenting information. Usually, in the spatial analysis and geographical mapping, small spatial areas should be used such as districts, counties, ..., etc. But in this research governorates were used which considered somewhat larger than for example the districts because the data were not available for smaller areas. Most often the word "neighbourhood" suggested a relatively small area surrounding individuals' homes but researchers commonly make use of larger spatial area such as census tracts (Coulton, Korbin, Chan, and Su, 2001). However, it was noteworthy that Jordan is relatively small country in area and in population, so the governorates can be considered as small spatial areas. Often, choices about neighbourhood spatial definitions were made with respect to convenience and availability of contextual data rather than study purpose (Schaefer-McDaniel, Caughy, O'Campo, and Gearey, 2009). The authors stated that, researchers might utilize census data and thus rely on census-imposed boundaries to define neighbourhoods even thought theses spatial areas may not be the best geographic units for the study topic.

Significant spatial interaction between neighbouring UR implies that cross-section data is marked by a positive spatial autocorrelation. In this case, similar values, either high or low, are more spatially clustered than could be caused by chance. In contrast to the clearly defined autocorrelation in time-series, the dependence is multidirectional in the spatial case. Local values that are very different from the mean or median would indicate locations that contribute more than their expected share to the global statistic. These may be outliers or high leverage points and thus would invite closer scouting. Moran's $I_{i}$ served two purposes or provided two interpretations (Anselin, 1995). First, it may be interpreted as indicator of hot spots. Second, it may be used to assess the influence of individual locations on the magnitude of the global Moran statistic and to identify outliers.

As noted by Waller and Jacques (1995) the test for spatial pattern employs alternative hypotheses of two types; the omnibus not the null hypothesis or more specific alternatives. Tests with specific alternatives include focused tests that are sensitive to monotonically decreasing risk as distance from a putative exposure source (the focus) increases. Acceptance of either types (the omnibus or a more specific alternatives) only demonstrates that some spatial pattern exist, and does not implicate a cause (Jacques, 2004). Hence the existence of a spatial pattern alone cannot demonstrate nor prove a causal mechanism. However, the existence of unemployment clusters, i.e., similar labour market conditions 
in neighbouring governorates suggests that policies that promote labour mobility across longer distances might be appropriate to reducing differences in unemployment.

Economic and social implications from unemployment in Jordan were found by the study of Amerah (1993). The economic implications included the decline in production, cost of supporting the unemployed, education cost, decrease in the wage level, and effects on governorate revenues. The social implications included the psychological effects, impact on the living standard, health effects, social ties, the accommodations standard, effect on children education, and other effects. Based on the survey study by Amerah (1993), the highest UR was in Karak (28.5\%), followed by Tafilah (20.3\%) and Ma' an (17\%) while in this study in 2008, the highest UR was in Ma'an followed by Karak and Tafilah as shown in Table 1. Compared to 1991 the UR was decreased in 2008 in both Karak and Tafilah but it was slightly increased in Ma'an. Means that the problem of unemployment in Ma'an was probably came from the neighbouring governorates, firstly from Karak and secondly from Tafilah. In addition, the results in this study are coincided with the results provided by Amerah that showed the importance of studying the unemployment dimensions across governorates in Jordan.

Regional UR is highly correlated in space, since they change usually by small amounts and often in same directions simultaneously across space (Elhorst, 2001). As the spatial clusters of unemployment in Jordan are found, most probably there are several variables that affect the unemployment. For example, the Jordanian population is relatively young, which is equivalent to saying that the birth rate is relatively high, a result of which a governorate's population growth rate exceeds its employment growth rate. Also, the labour force participation rate and the migration rate are relatively high.

The application of statistical techniques to spatial data faces an important challenge, as expressed in the first law of geography: "everything is related to everything else, but closer things are more related than distant things" (Tobler, 1979). The quantitative expression of this principal was the effect of spatial dependence, i.e., when the observed values were spatially clustered, the samples were not independent. Employment growth in governorate $i$ generates employment growth in governorate $j$. This mechanism of transmission causes a spatial autocorrelation of employment growth. The obvious question after finding significant clusters of UR was-why? Could this pattern associated by the spatial pattern of socioeconomic indicators such as the levels of education or by the limitation of economic resources? However, further research is required regarding this bivariate spatial association between UR and socioeconomic indicators which will be my interest in the near future. This paper adds to the global body of knowledge on the utilization of spatial analysis to strengthen the research-policy interface in the developing countries. Although, this work was conducted as part of a wider study, its immediate implications are more for policy makers and practitioners than for researchers.

It should be emphasized that unemployment problem cannot be overcome in the shortrun but long-term efforts are needed to tackle the inequalities across governorates, and in turn, enabling the economy to create more job opportunities and to establish new projects especially in the governorates that found as hot spot clusters. It means that the place of the problem is now clearly shown. Also, efforts should be made to aware the public through the media and education system about the labour market requirements of various specializations and occupations in the coming years. This would assist students to specialize in 
the required occupations instead of increasing the number of unemployed in not needed occupations. Also, offering free training courses to the unemployed in the hot-spot clusters should be help to overcome the problem of unemployed. However, the author agree with the suggestions of Amerah (1993) about government policies in Jordan to alleviate unemployment inequalities in the hot spot clusters, such as: activating the role of public health institutions and promoting the coordination among them, improving the public sector procedures with regard to the recruitment of qualified staff, and establishing a national information scheme to include data and information related the various aspects of Jordanian labour market. Finally, unemployment studies should be conducted periodically in light of the changing socioeconomic and political conditions.

\section{Conclusions}

Global clustering and local clusters for UR were studied. The results were conclusive in at least four aspects. First, visual inspection showed that high levels of UR was concentrated in the central and southern parts of the country, for instance in the governorates 7, 9, 10 and 11. Second, three governorates 4, 5 and 6 were not observed visually as hot spots, but after considering the information of their neighbours, i.e., calculating their local Moran's $I_{i}$ values, the patterns of their hot spots can be obviously seen in Figure 3 . Third, global clustering wasn't found for UR, but several governorates were found to be local clusters in the central and western-southern part, where they were 5, 6, and 10. The opposite being the case for those with low unemployment was seen in the northern part. Forth, from negative local Moran values, looking at the local variation, some of governorates represented as areas of dissimilarity, for example, governorates 3 and 7; means that governorate with low UR surrounded by governorates with high UR or vice versa. Massive layoffs in a certain governorate will tend to depress adjacent labour markets as well. Likewise, every measure that reduces local unemployment will also have positive effects in neighbouring labour markets. This calls for close cooperation and common measures between governorates in order to diminish labour market problems.

The analytical approach used here accurately delineates governorates of relatively high UR, and permits policy makers to develop strategies in way that should minimize the UR inequalities between governorates. Policy which pays attention to area characteristics will diminish UR inequalities and consequently improve the prosperity which in turn will improve the health status. In summary, the study supports the hypothesis of a spatial inequality in UR at area level that probably reflects the governorate distribution of education level. Further research is required to study the spatial pattern of education variable and the distribution of job chances offered by the country and their bivariate spatial association with spatial pattern of unemployment in attempting to interpret the spatial clusters in UR.

\section{References}

Amerah, M. (1993). Unemployment in Jordan: dimensions and prospects (Tech. Rep.). Center for International Studies. (http://library.fes.de/pdf-files/bueros/vifa- 
nahost/b93_00075.pdf)

Anselin, L. (1995). Local indicators of spatial association - LISA. Geographical Analysis, 27, 93-115.

Bertola, G. (1999). Microeconomic perspectives on aggregate labour markets. In O. Ashenfelter (Ed.), Handbook of Labour Economics (p. 2985-3028). Amsterdam: Elsevier.

Blau, F. D., and Kahn, L. M. (1999). Institutions and laws in the labour market. In O. Ashenfelter (Ed.), Handbook of Labour Economics (p. 1399-1461). Amsterdam: Elsevier.

Buettner, T. (1999). The effect of unemployment, aggregate wages and spatial contiguity on local wages: An investigation with german district level data. Papers in Regional Sciences, 78, 47-67.

Cattaneo, C. (2006). The determinants of actual migration and the role of wages and unemployment in Albania: an empirical analysis. Liuc papers, No. 196, Serie Economia e Impresa, 50, 1-35. (http://www.biblio.liuc.it/liucpap/pdf/196.pdf)

Cliff, A. D., and Ord, J. K. (1981). Spatial Processes: Models \& Applications. London: Page Bros.

Coulton, C. J., Korbin, J., Chan, T., and Su, M. (2001). Mapping residents' perceptions of neighbourhood boundaries: A methodological note. American Journal of Community Psychology, 29, 371-383.

Eichengreen, B. (1993). Labour markets and European monetary unification. In P. R. Masson and M. P. Taylor (Eds.), Policy Issues in the Operation of Currency Unions. Cambridge: Cambridge University Press.

Elhorst, J. P. (2001). The mystery of regional unemployment differentials; a survey of theoretical and empirical explanations (Tech. Rep.). (http://som.eldoc.ub.rug.nl/FILES/reports/themeC/2000/00C06/00C06.pdf)

Elhorst, J. P. (2003). The mystery of regional unemployment differentials: Theoretical and empirical explanations. Journal of Economic Survey, 17, 709-740.

Filiztekin, A. (2007). Regional Unemployment in Turkey (Tech. Rep.). (http://www.ecomod.org/files/papers/486.pdf)

Jacques, G. M. (2004). Current practices in the spatial analysis of cancer: flies in the ointment. International Journal of Health Geographics, 3, 1-10. (http://www.ijhealthgeographics.com/content/3/1/22)

Koch, T. (2005). Cartographies of Disease: Maps, Mapping, and Medicine. California: Guilford Press.

Lawson, A. B., and Williams, F. R. (2001). An Introductory Guide to Disease Mapping. New York: Wiley \& Sons.

Layard, R. (1997). Preventing long-term unemployment: an economic analysis (with discussion). In D. J. Snower and G. de la Dehesa (Eds.), Unemployment Policy. Cambridge: Cambridge University Press.

Lopez-Bazo, E., Barrio, T., and Artis, M. (2000). The geographical distribution of unemployment (Tech. Rep.). (http://www.eco.ub.es/ elopez/geounemp.pdf)

Macintyre, S., Maciver, S., and Sooman, A. (1993). Area, class, and health: Should we be focusing on places or people? Journal of Social Policy, 22, 213-234.

Manning, N. D. (1994). Earning, unemployment and contiguity: evidence from British 
countries 1976-1992. Scottish Journal of Political Economy, 41, 43-68.

Molho, I. (1995). Spatial autocorrelation in british unemployment. Journal of Regional Sciences, 35, 641-658.

Overman, H. G., and Puga, D. (2002). Unemployment Clusters across Europe's Regions and Countries. Economic Policy. Oxford: Blackwell.

Schabenberger, O., and Gotway, C. A. (2005). Statistical Methods for Spatial Data Analysis. Boca Raton: Chapman \& Hall.

Schaefer-McDaniel, N., Caughy, M. O., O'Campo, P., and Gearey, W. (2009). Examining methodological details of neighbourhood observations and the relationship to health: A literature review. Social Science \& Medicine, 70, 277-292.

Tobler, W. R. (1979). Cellular geography. In S. Gale and G. Olsson (Eds.), Philosophy in Geography (p. 379-386). Dortrecht: Reidel Publishing Company.

Waller, L. A., and Gotway, C. A. (2004). Applied Spatial Statistics for Public Health Data. New Jersey: Wiley \& Sons.

Waller, L. A., and Jacques, G. M. (1995). Disease models implicit in statistical tests of disease clustering. Epidemiology, 6, 584-590.

Weeks, J. R. (1992). Population: An Introduction to Concepts and Issues (5th ed.). Belmont, CA: Wadsworth Publishing.

Authors address:

Faisal G. Khamis

AL-Zaytoonah University of Jordan

Faculty of Economics and Administrative Sciences

P.O. Box 130

Amman 11733

Jordan

E-Mail: faisal_alshamari@yahoo.com 